\title{
EL FEMINISMO ÁRABE Y SU LUCHA POR LOS DERECHOS DE LA MUJER ${ }^{1}$
}

\author{
NiEVES PARADELA \\ Profesora titular de Estudios Árabes, UAM
}

Recibido: $27 / 08 / 2015$

Aceptado: 11/09/2015

\section{Resumen}

En el presente artículo se efectúa un análisis de las diversas etapas por las que ha transitado el feminismo árabe desde su aparición, a finales del siglo XIX, hasta hoy. La lucha por el derecho a la educación de las mujeres, al trabajo, y a la igualdad jurídica se articuló, durante una primera fase, en un discurso nacionalista y laico que defendía tanto la independencia nacional -en unos años en los que el mudo árabe vivía aún bajo dominio colonial europeo- como la consecución de una deseada modernidad social y política. En la cuestión del velo -que más allá de una obsesión occidental cierta, fue también un asunto muy debatido entre las propias mujeres-, la opción preferente fue la de su eliminación. Los innegables logros obtenidos no impidieron la continuación de sus demandas de derechos políticos y de derogación del derecho familiar basado en la sharía. Un sesgo significativo se produjo a partir de los años 70 del siglo XX con el proceso de reislamización de las sociedades árabes. El así llamado «feminismo islámico» emergió entonces como un discurso potente y muy visible, incluso en nuestro mundo occidental, que no ha logrado, sin embargo, eliminar el feminismo laico y combativo de ya larga historia.

\begin{abstract}
This article analyses the main historical and ideological features which have characterized Arab feminism since its origins in the second half of XIX century until nowadays. In its initial phase, Arab feminism was articulated within a nationalistic and

1. Este artículo apareció originalmente en el n. ${ }^{\circ} 46$ (enero-abril, 2014) de Encuentros Multidisciplinares (UAM). Las editoras de este número de Feminismos han considerado adecuada su reimpresión en atención a su interés y a su adecuación al tema del monográfico.
\end{abstract}

Feminismo/s 26, diciembre 2015, pp. 17-29

DOI: $10.14198 / \mathrm{fem} .2015 .26 .02$ 
secular discourse, and the first women's organizations worked hard in defence of girl's education, female work and the achievement of legal equality. On the very sensitive issue of wearing the hijab or not, most urban and learned women were against it. With the reislamization of Arab societies -a process that arose in the 70's of XX century- the so-called «Islamic feminism» appeared both in Arab societies and in western countries. This is a new and controversial phenomenon that coexists -sometimes in harmony, others showing their strong differences- with secular and liberal feminism. 


\section{El nacimiento del feminismo árabe. Las mujeres y la nación}

El 20 de mayo de 1928 se inauguró oficialmente en El Cairo una escultura encargada por el gobierno de Egipto -un país que había logrado su independencia de Gran Bretaña sólo seis años antes- al destacado artista local Mahmud Mujtar. El espectacular conjunto escultórico, al que se dio el nombre de El despertar de Egipto, representaba a una mujer de pie, con el brazo derecho colocado sobre la cabeza de una esfinge en posición semierguida. La simbología nacionalista de la imagen es evidente: el nuevo estado reconocía su vínculo histórico con el pasado faraónico (rechazando implícitamente que su origen estuviera en la conquista árabo-islámica del siglo VII), y además la nación quedaba representada iconográficamente mediante una figura femenina, algo por otra parte muy frecuente en las ilustraciones y viñetas que proliferaban en la dinámica prensa de la época, y que también demostraba el influjo de las tradiciones iconográficas europeas en las que la nación era pensada y representada como mujer. Egipto era, en suma, mujer ${ }^{2}$, como Francia era Marianne o España era dibujada o esculpida como una fecunda matrona, tocada, según épocas, bien con corona, bien con gorro frigio.

Pero si concentramos nuestra atención en la figura de la mujer, veremos que su mano izquierda está ejecutando una acción bien precisa: la de levantar un velo o un pañuelo de su cabello. Un detalle no menos significativo que el primero y que nos permite concluir que entonces Egipto era una mujer desvelada o, al menos, una mujer desvelándose. Aquel mensaje de signo nacionalista, pero también inequívocamente feminista, que Mujtar grabó en piedra y que recibió la aceptación de la élite política e intelectual del Egipto independiente, resultó posible porque desde mediados del siglo XIX había comenzado a producirse un vigoroso movimiento en defensa de los derechos de las mujeres, cuyos protagonistas -mujeres y hombres- entendían que el atraso de los países árabes o musulmanes era debido, en parte, a la situación en la que vivían sus mujeres y que, en consecuencia, la nación no podría prosperar si no lo hacían también ellas. Ese primer feminismo -desarrollado en su fase inicial

2. Ver Baron y Ruiz-Almodóvar (1989). 
en Egipto y en Siria-Líbano, pero cuyas características esenciales se reproducirían luego en el resto de países árabes- fue sobre todo un feminismo burgués, ilustrado y con profundas vinculaciones con el pensamiento nacionalista y reformista de la época.

Hind Nawfal, una joven periodista libanesa afincada en Alejandría, fundó en 1892 la que sería la primera revista dedicada en exclusiva a las mujeres árabes. La tituló Al-Fatat, es decir, La muchacha. Y, aunque esta especialización no fue del todo infrecuente, lo cierto es que mujeres, y hombres, recurrieron a todo tipo de prensa (desde la generalista a la de partidos políticos) para exponer sus opiniones sobre un tema que enseguida se convertiría en uno de los más notables del momento. Entre las más prolíficas escritoras estuvo Malak Hifni Nasif (1886-1918), quien en 1909 publicó un libro que recogía sus cerca de sesenta artículos - antes aparecidos en periódicos y revistas- dedicados a la defensa de lo que ya era, y así se nombraba, la cuestión femenina. Los temas abordados iban desde la crítica a la poligamia o a los matrimonios forzados, a la defensa de la educación para las niñas (asunto este, el de la educación, central para toda aquella primera generación de feministas árabes), sin olvidar, por supuesto, la cuestión del velo que también suscitaba entonces viva polémica. En términos generales, las mujeres -entendiendo bien su significado patriarcal y segregador, y las más cultas, además, su nula justificación desde un punto de vista religioso- abogaban por no utilizarlo o por desprenderse de él. El desvelamiento debía ser -y lo era, de hecho- uno de los signos indumentarios de la nueva mujer. Sin embargo, algunas de ellas (Hifni Nasif, por ejemplo), si bien participaban en teoría de esta visión, se mostraban algo más cautas al respecto, pues entendían que la tradición aún dominaba los comportamientos sociales, y que sólo el día en que los hombres fueran educados para aceptar y respetar a las mujeres libres y desveladas, el velo habría perdido su razón de ser. No todas fueron tan prudentes, como veremos a continuación, y no esperaron al hipotético surgimiento del nuevo hombre árabe para desprenderse del velo y reclamar al tiempo sus derechos políticos.

Aun con todo, los hombres iban cambiando, y algunos tomaron abierto partido por la liberación de la mujer. Tal fue el caso del abogado egipcio, Qasim Amin, autor de dos importantes obras sobre el tema: La liberación de la mujer (1899) y La nueva mujer (1900) ${ }^{3}$. Pero, sin duda, la figura más representativa de este primer feminismo árabe fue la egipcia Huda Shaarawi (18821947). De origen aristocrático, trabajó durante toda su vida en favor de la educación de las mujeres y de conseguir dotarlas de un marco organizativo

3. De esta última obra hay traducción al español: La nueva mujer (2000). 
y de una actuación pública que resultaron esenciales para el desarrollo del feminismo egipcio y árabe. Logró que las autoridades le permitieran celebrar reuniones en la recién creada Universidad Egipcia (1908), antes de que se admitiera su ingreso como estudiantes, lo que acaeció finalmente en 1929; en 1914 fundó la Asociación Intelectual de Mujeres, y en 1919 pudo movilizar a un notable número de mujeres que participaron en las grandes manifestaciones que se produjeron por todo el país para reclamar la independencia de Gran Bretaña ${ }^{4}$. Se trató, este último, de un hecho crucial, en el que las mujeres no sólo tomaron posesión de un espacio público antes reservado casi en exclusiva a los hombres, sino que al enarbolar banderas, corear proclamas o arengar a las multitudes, defendieron también su condición de ciudadanas en demanda de libertad. Una libertad colectiva, pero también personal.

Shaarawi era la esposa de un destacado líder nacionalista, cofundador del gran partido político -el Wafd-que negoció con Gran Bretaña la independencia de Egipto. Este vínculo personal, y un indudable interés mutuo, impulsaron a Huda a fundar el Comité Central de Mujeres del Partido Wafd que, sin embargo, no duró mucho. Al enterarse de que el documento que había preparado el Wafd para negociar con los británicos el tratado de independencia no se les había siquiera mostrado a ellas, Shaarawi disolvió la agrupación y ya no volvió a haber colaboración orgánica con el partido. Todo indicaba que las mujeres tendrían que luchar no sólo sin el apoyo de los partidos políticos o de los regímenes nacidos tras las independencias, sino, en muchas ocasiones, contra ellos.

En 1923, Huda Shaarawi fundó la Unión Feminista Egipcia y tuvo el honor de representar por vez primera a su país -ya un estado oficialmente soberano- en un congreso feminista que se celebró en Roma. Y fue al regresar a El Cairo cuando esa mujer -muy consciente de la contradicción a la que antes aludimos- decidió quitarse el velo ante la multitud que había ido a recibirla a la estación de tren de El Cairo. En Roma había representado a un país recién liberado, se había movido, naturalmente, sin velo, y ahora, esa ciudadana -orgullosa de serlo- volvía a Egipto y debía taparse el rostro. No lo aceptó y dejó muestra patente de su negativa, en un gesto que figura con todo merecimiento en los anales del feminismo árabe.

Pero había muchos más problemas. Cierto es que los niveles de alfabetización y de educación -en todos los niveles- mejoraban, y que la incorporación al trabajo iba, poco a poco, produciéndose; pero, por un lado, el nuevo estado no les otorgó el derecho al sufragio ni a la elección y, por otro, el derecho de

4. En la autobiografía de Shaarawi se relatan con precisión estos sucesos.

Feminismo/s 26, diciembre 2015, pp. 17-29 
familia era, en su conjunto, y sin paliativo alguno, discriminatorio para con ellas. Y en todos estos frentes dieron batalla. Ausentes del parlamento, las mujeres recurrieron a otros foros -la prensa, las asociaciones feministas, la calle- para hacerse oír y provocar respuesta a sus demandas. Entretanto, la Unión Feminista Egipcia crecía y se internacionalizaba, estableciendo vínculos con muchas otras agrupaciones afines creadas en el resto de países árabes (especialmente del Oriente árabe). El contacto con los movimientos de mujeres palestinas -que sumaban a su lucha feminista la defensa de su nación frente al sionismo- fue especialmente relevante.

Con una creciente concienciación política -y en un entorno que les negaba gran parte de sus derechos individuales y todos los políticos-, no es extraño que el asociacionismo feminista creciera y se diversificara, haciendo que apareciesen en escena dirigentes con una formación académica más sólida que la de Shaarawi y pertenecientes a nuevos estratos sociales. En este sentido destaca la figura de Durriya Shafik (1908-1975), una mujer procedente de la clase media que, tras completar sus estudios en la Universidad Egipcia obtuvo un doctorado en La Sorbona (1931). Su lucha fue predominantemente política: en varias ocasiones movilizó a las mujeres frente al Parlamento en protesta por su forzada ausencia del mismo, llevó a cabo una huelga de hambre y sufrió un largo arresto domiciliario. En 1952 creó la asociación Bint al-Nil (La hija del Nilo) e intentó infructuosamente presentarse a las elecciones. Las dificultades eran evidentes, pero el movimiento feminista crecía: el órgano de prensa de su asociación, la revista Bint al-Nil, editaba mensualmente 15.000 ejemplares que se distribuían por todo el mundo árabe.

Así, tras la muerte de Shaarawi y a las puertas de la toma del poder por Naser, el feminismo egipcio se había convertido en un movimiento potente y combativo que reclamaba cambios en las esferas pública y privada de las mujeres. En todo el mundo árabe, las décadas de los años 50 y 60 supusieron el acceso a las independencias nacionales, el predominio de la ideología panarabista y la vivencia de un tiempo de claro optimismo histórico. Sin embargo, la coexistencia de estados sociales con la siempre postergada cuestión de la democracia política mostró muchas de sus contradicciones en lo referido a las mujeres. Cierto es que el número de universitarias creció extraordinariamente, cierto es que en Egipto la mujer consiguió el derecho al voto y a la elección en 1956, aunque incluso un año antes Naser designó a Aziza Ahmad Husayn como representante de Egipto ante la ONU, y en 1961 por vez primera se nombró ministra a una mujer: Hikmat Abu-Zayd, de Asuntos Sociales. Sin embargo, el régimen naserista (como tantos otros en el mundo árabe), al prohibir los partidos políticos y gran parte de las asociaciones de 
corte cívico y religioso, infligió un duro golpe al feminismo más reivindicativo, sustituyéndolo por otro más oficial y más controlable. Muchas mujeres entraron por aquellos años en prisión, tanto quienes pertenecían a grupos de izquierda como quienes defendían posiciones radicalmente opuestas.

Tal fue el caso de Zaynab al-Gazzali (1917-2005), una mujer que tras militar en la Unión Feminista de Shaarawi y abandonarla tachándola de «occidentalista», había fundado en 1936 la Asociación de Damas Musulmanas. Se trataba de una agrupación de pensamiento islamista que rechazaba la ideología nacionalista y semilaica del régimen, y defendía la implantación de un estado islámico regido por la sharía (la ley islámica), en el que -según su opinión- las mujeres tendrían reconocidos por esa misma sharía todos sus derechos. Era, sin duda, la misma ideología islamista de los Hermanos Musulmanes y, de hecho, los dirigentes de la Hermandad intentaron convertir a la Asociación en una especie de sección femenina suya, a lo que Gazzali se negó, en un gesto idéntico al de Shaarawi pocos años antes. Las ideologías de una y de otra podrían diferir, y mucho, pero del carácter patriarcal y machista de las agrupaciones masculinas -fueran nacionalistas, liberales o islamistasno dudaba ninguna de ambas. Obvio es decir que Gazzali defendía el velo, aunque por entonces la mayoría de mujeres no lo vestían y, lejos de creer en las potenciales bondades de la sharía para con ellas, seguían presionando al régimen para que aboliera las leyes de familia que, en su conjunto, atentaban gravemente contra la igualdad jurídica de las mujeres.

Estas leyes, conocidas como «códigos de familia» o «códigos de estatuto personal» son la parte del corpus jurídico de cualquier estado musulmán que rige las cuestiones relativas a la filiación, la herencia, el matrimonio, el divorcio, la custodia de los hijos, etc. Y si bien el resto de leyes (sean las del derecho civil general, el penal, el administrativo, etc.) han salido hoy del ámbito de la sharía y responden al fundamento de todo derecho positivo, las relacionadas con el estatuto familiar de las mujeres siguen extrayendo su contenido (en mayor o menor medida ya que no están unificadas) de la legislación islámica medieval ${ }^{5}$. La demanda de abrogación de estos códigos sigue siendo el centro de las exigencias de muchos de los movimientos feministas árabes actuales.

5. Frente a una opinión muy difundida, la sharía no tiene consideración de ley divina, y por ello es susceptible, incluso desde posiciones ortodoxas, de ser modificada o abrogada. Dentro de los códigos de familia ha habido países que han introducido cambios radicales (Túnez y su prohibición de la poligamia en los años del régimen de Bourguiba) o pasos más tímidos para suavizar varios de sus aspectos más polémicos. La reforma del código marroquí de 2004 no llegó a prohibir la poligamia, pero la limitó y dio más poder de decisión a la mujer. Para una visión de conjunto, ver Ruiz-Almodóvar (2005). 


\section{La reislamización de las sociedades árabes. Feminismos polarizados}

A partir de los años 70 del siglo XX, tanto los estados como las sociedades del mundo árabe iniciaron un giro ideológico que alteró de raíz la situación conocida hasta entonces. La pervivencia de regímenes no democráticos, sumada a la inclusión de la mayoría de países en la esfera de influencia de EE.UU. (que garantizaba la estabilidad política de las dictaduras y fomentaba la implantación de una economía capitalista que, en ausencia de un desarrollo económico anterior, acrecentó extraordinariamente la brecha entre ricos y pobres), y al fracaso del panarabismo -cuyo mayor símbolo fue la imposibilidad de derrotar militarmente a Israel e implantar el estado palestino-, son algunas razones que lo explican. Pero fue sobre todo el espectacular enriquecimiento de los países del Golfo (con Arabia Saudí a la cabeza), gracias al petróleo, lo que determinó en última instancia el sesgo ideológico que tomó la crisis de los 70. Los petrodólares no sirvieron sólo para que se modernizaran tecnológicamente países con formas de vida preindustriales, sino también para exportar al resto del mundo árabe un modelo de islam tradicional, estricto, conservador y antimoderno que fue muy bien acogido por el resto de estados árabes, no sólo necesitados de dinero, sino convencidos de que aquel incremento del discurso islamista, aquella reislamización de las sociedades, conseguiría frenar-incluso más contundentemente que las fuerzas policiales o el ejército- el descontento popular, tanto el que demandaba pan como el que exigía democracia y libertades.

La vuelta al islam, iniciada entonces y cuyos efectos aún perduran, no aconteció por ninguna razón esencialista: fue pagada con dinero saudí, bien recibida e implantada por los regímenes árabes autoritarios, y permitida y aplaudida-con mayor o menor sordina-por EE.UU. Antes o después, muchos de los dirigentes políticos árabes y, también, EE.UU., tuvieron luego razones de peso para lamentarse de aquello que contribuyeron a crear.

Estas circunstancias explican el retroceso evidente que sufrieron las mujeres en su lucha por la igualdad. La crisis económica y la escasez de empleo forzaron a muchas a volver al ámbito doméstico, y en calles y en aulas comenzó a imponerse el velo o la indumentaria islámica completa. Es fácil entender el desencanto con que muchas profesoras universitarias -cuyo acceso a la educación superior y al trabajo fueron fruto de aquel primer feminismo liberal e ilustrado- contemplaban cómo, una tras otra, sus jóvenes estudiantes iban entrando a clase tocadas con el hiyab. A veces podía ser imposición paterna -o todo lo contrario, rebeldía ante su prohibición-, o de novios o maridos, o creencia de que sin él el matrimonio no llegaría, o -más pragmáticamenteprotección frente al acoso sexual, pero siempre existía una indudable presión 
social y un cada vez más publicitado énfasis en la identidad personal o colectiva -«yo soy musulmana»-y en la necesidad de visibilizarla a través del velo. Resulta contradictorio, pero así era.

No todas se plegaron y, aun en circunstancias complicadas, el discurso feminista reivindicativo y laico siguió existiendo. Quizá la figura que mejor lo representó fue la de Nawal al-Saadawi (n. 1931). Médica de profesión y especialista en salud mental, a ella se debe la introducción del debate sobre el sexo en las sociedades árabes con su obra de 1972 Mujer y sexo ${ }^{6}$. Ha sido una destacada activista, cofundadora de la Asociación Árabe de Derechos Humanos (1983) y fundadora de la Asociación de Solidaridad con la Mujer Árabe (1985). Esta última agrupación fue clausurada en 1990 por el expresidente Mubarak. Durante varios años ha vivido fuera de su país, amenazada por grupos islamistas, y tras el desencadenamiento de las revueltas árabes ha regresado a su país.

Sin embargo, la correlación de fuerzas ideológicas se había alterado de forma radical. Lo que antes era un discurso residual y minoritario, ahora se convertía en otro dominante y mayoritario. Se teorizaba sobre el necesario estado islámico, se acuñaba el lema "el islam es la solución», e inevitablemente iba configurándose un subdiscurso islamista sobre la mujer que sólo en la década de los años 90 llegaría a ser nombrado como «feminismo islámico», y que en una porción nada desdeñable se generó en ambientes universitarios occidentales, tanto de Europa como de EE.UU. Fundamentándose en la teoría poscolonial y recurriendo a conceptualizaciones de signo culturalista, este nuevo feminismo, tras realizar una severísima crítica al feminismo árabe liberal y laicista -tachándolo sin ambages de imperialista o neocolonial- defiende que la verdadera liberación de la mujer (musulmana, por supuesto) no está en el abandono de la propia cultura -entendida, claro, en términos religiosos- y en la adopción de valores extranjeros, sino en la vuelta al islam, en la aplicación de la sharía, una vez, eso sí, depurada de todas las falsas interpretaciones acumuladas tras siglos de exégesis coránica masculina y patriarcal.

Una de las figuras más representativas hoy de esta tendencia es Amina Wadud (n. en 1950), una mujer afroamericana convertida al islam, profesora en la Universidad de Michigan y autora de dos destacadas obras sobre el tema: Qur'an and Woman. Rereading the Sacred Text from a Woman's Perspective (1995) e Inside the Genre Jihad: Women's Reform in Islam (2006). Wadud completa su labor académica con un notable activismo público, y su valiente defensa del imamato (la dirección del rezo colectivo en las mezquitas y la pronunciación

6. Este libro no cuenta con traducción al español. Pero sí otro ensayo suyo: La cara desnuda de la mujer árabe, 1991. 
del sermón posterior) femenino le llevó a ponerlo en práctica ella misma en 2005 en Nueva York y en 2008 en Barcelona, durante la celebración de un congreso al que fue invitada. Como en ninguna de las dos ciudades obtuvo permiso para hacerlo en una mezquita, en Nueva York reunió a sus fieles en la iglesia presbiteriana de San Juan, y en Barcelona en un salón del hotel en el que se celebraba el congreso. Muy pocos hombres asistieron a estos oficios y, desde luego, el islam oficial y tradicional condenó duramente los hechos y a su protagonista.

Si bien este feminismo islámico resulta difícilmente entendible -por su énfasis en la religión, por su lenguaje y conceptos culturalistas, y por su antiuniversalismo- para los sectores laicistas y progresistas de las sociedades árabes, forzoso es reconocer que su perspectiva de género aplicada a la lectura de los textos religiosos, su condena al patriarcalismo imperante en las cúpulas dirigentes del islam y su reivindicación de un mayor papel de las mujeres en todo ello -elementos que tanto se asemejan a la labor de teólogas, y teólogos, cristianos progresistas- lo hacen atractivo e interesante. Al menos -o sólointelectualmente hablando.

La reaparición del velo femenino en los países musulmanes -y también en las comunidades de origen musulmán implantadas en Occidente- vino acompañada de un discurso justificativo que a veces se asemejaba al tradicionalista (y su significado era entonces el de proteger la moral personal, familiar y del grupo), otras recogía en parte argumentos ya escuchados a comienzos del siglo XX (ante el acoso sexual de los hombres y la mercantilización del cuerpo femenino practicada en Occidente -decían-, la mujer hará bien en recurrir a la indumentaria islámica para evitar problemas y poder seguir estudiando o trabajando), pero que cada vez más insistentemente se nutría de conceptualizaciones culturalistas e identitarias. Las mujeres que compartían esta visión de sí mismas habían pasado de sentirse en primera instancia marroquíes, egipcias o palestinas para ser, antes que cualquier otra cosa, musulmanas. Y el velo era su bandera visible. El islam se convertía así en una identidad fuerte y en un movimiento que podía llegar a derrocar regímenes corruptos, como sucedió en Irán en 1979.

En Europa, este discurso identitario de raíz religiosa prendió bien, no sólo entre muchas jóvenes de las segundas o terceras generaciones de inmigrantes, sino también entre una izquierda tanto política como intelectual -y académica- que, aparcando su tradicional suspicacia hacia el protagonismo social y político de la religión (al fin y al cabo, opinarían con notable falta de información, el islam no es sólo una religión, no es una religión como las otras y además está luchando contra regímenes corruptos apoyados por 
EE.UU.) y aplaudiendo, esta vez sin dudas, la opción indigenista que, en su óptica, representaba el islamismo, renunció a sus convicciones universalistas y defendió la indumentaria islámica como expresión de una identidad libremente elegida y como ejemplo del derecho a rechazar valores propios de unas culturas que habían sido impuestos a otras.

Es esta, inexplicable para muchos, connivencia entre el discurso islamista y el de una izquierda europea cada vez más posmoderna y antiilustrada, la que combate con vigor y argumentos sólidos Wassyla Tamzali (n. en 1941), una abogada argelina de origen y residente en Francia desde hace años. Se define a sí misma como «mujer de cultura musulmana, feminista, laica y librepensadora»y, tanto en sus libros ${ }^{7}$, artículos y numerosas intervenciones públicas critica con fuerza la mera posibilidad de que pueda existir algo denominado «feminismo islámico»y, sobre todo, el apoyo que recibe, bien sea de esa izquierda (a la que ella pertenece por formación y convicción), bien sea de muchas instituciones públicas nacionales o supranacionales. Así escribía en 2010:

Europa, a falta de poder intervenir en problemas esenciales que dividen al norte y al sur del Mediterráneo, como la cuestión palestina o la circulación de personas, se pierde en acciones inútiles y a veces mortíferas. El feminismo islámico no sólo tiene derecho de ciudadanía en los debates sobre la sociedad civil, sino que ahora tiene la exclusividad, o casi. Los organizadores de estos encuentros, numerosos y generosamente financiados por la Unión Europea, excluyen desde hace algunos años de las discusiones las formas marxistizantes y universales de la crítica social para favorecer los enfoques culturalistas y diferenciales. (El burka como excusa, 24)

Sin embargo, y a pesar de que alguna vez ha declarado entre irritada e irónica que es tanta la visibilidad que el velo proporciona al discurso islamista que ella, y las que piensan como ella, tendrían que ponérselo para que sus ideas recibieran atención, lo cierto es que es una figura conocida en el panorama intelectual francés, y como tal ha participado en debates políticos relevantes. En 2003 fue invitada a comparecer ante la comisión parlamentaria que preparaba la Ley del Velo y, si bien el velo musulmán fue finalmente prohibido, Tamzali criticó que la ley lo hubiera equiparado finalmente a otros elementos de significado religioso, como el crucifijo o la kipá judía. Argüía que entender que el velo es un mandato religioso (no lo es, en absoluto) o un signo de

7. En español hay traducidos tres: El burka como excusa (2010), que incluye un dossier preparado por Itziar Elizondo acerca del debate sobre el velo en España; Carta de una mujer indignada (2011) y Mi tierra argelina. Una mujer entre la revolución y la guerra civil (2012).

Feminismo/s 26, diciembre 2015, pp. 17-29 
expresión religiosa (sólo lo es en parte) -olvidando las varias otras cosas que también es-, terminaba por dar la razón a los islamistas en su estrategia de control patriarcal sobre las mujeres.

Su defensa de un feminismo laico y universalista (es recomendable consultar el texto del Manifeste des Libertés que ella misma contribuyó a crear: www.manifeste.org) es heredera tanto de los valores emancipatorios europeos surgidos a partir del XVIII, como de los primeros movimientos feministas árabes. Y siendo muy consciente de las dificultades en las que ahora se mueve su pensamiento, cree que éste no ha agotado aún su papel histórico en las sociedades árabes.

\section{Final}

Hemos concluido este repaso a las principales etapas y corrientes del feminismo árabe haciendo referencia a dos pensadoras residentes en Occidente, y que enfocan el feminismo desde posiciones intelectuales radicalmente diferentes, porque la presencia de comunidades musulmanas entre nosotros, y la propia globalización, hace que necesariamente una parte del discurso feminista árabe se desarrolle en nuestros países ${ }^{8}$.

Es indudable, sin embargo, que su evolución va a estar mucho más ligada al desarrollo político, económico y social de los propios países árabes e islámicos. El crecimiento económico es necesario, pero no olvidemos que la mera existencia de riqueza no garantiza la igualdad entre hombres y mujeres, como demuestran Arabia Saudí y el resto de países del Golfo. Y que el islam -dicho así, en general- no es el único problema, lo acredita el que tanto con sistemas capitalistas o socialistas, con regímenes monárquicos o republicanos, las mujeres árabes han seguido sometidas a un orden jurídico y social discriminatorio e injusto.

Las recientes revueltas hicieron concebir esperanzas a gran parte de la sociedad civil que fue quien las inició y protagonizó. Esperanzas cifradas no sólo en el derrocamiento de los tiranos, sino sobre todo en la consecución de la ansiada democracia, única forma de gobierno que permitirá eliminar las desigualdades hoy existentes. El resultado no ha sido, ya lo sabemos, el esperado. El acceso al poder de partidos islamistas no es una buena noticia para las

8. También Francia se constituyó en 2003 un muy activo movimiento al que su fundadora, Fadela Amara (n. en 1964), dio el contundente nombre de Ni putes ni soumises (www.npns.fr). Bajo el eslogan Laicité, Égalité, Mixtité, la agrupación denuncia y combate el nuevo tradicionalismo que en nombre del islam se desarrolla en las banlieues de las grandes ciudades francesas habitadas por árabes y musulmanes de segundas y terceras generaciones. 
mujeres, que verán incrementada la islamización (léase retradicionalización) de sus sociedades y sufrirán la perpetuación de los injustos códigos de familia. Pero lo sucedido a continuación en Egipto, el golpe de estado, no augura la llegada de un panorama mejor. Tal vez sólo quede esperar, como opinaba Wassyla Tamzali, que la acumulación histórica de más de un siglo de lucha feminista árabe consiga seguir iluminando el muy ensombrecido escenario que hoy se vislumbra.

\section{Bibliografía}

BARON, Beth. Egypt as a Woman: Nationalism, Gender, and Politics. California: University of California Press, 2005.

Ruiz-Almodóvar, Caridad. Historia del movimiento feminista egipcio. Granada: Universidad de Granada, 1989.

Ruiz-Almodóvar, Caridad. El derecho privado en los países árabes. Códigos de Estatuto Personal. Granada: Universidad de Granada y Fundación Euroárabe de Altos Estudios, 2005.

SHAARAWI, Huda. Harem Years. The Memoirs of an Egyptian Feminist, 1879-1924. Londres: Virago Press, 1986.

As-SAADAWI, Nawal. La cara desnuda de la mujer árabe. Trad. María Luisa Fuentes. Madrid: Ed. Horas y horas, 1991.

TAMZALI, Wassila. El burka como excusa. Barcelona: Saga Editorial, 2010.

TAmzali, Wassila. Carta de una mujer indignada.Valencia: Ediciones Cátedra, 2011.

TAMZALI, Wassila. Mi tierra argelina. Una mujer entre la revolución y la guerra civil. Barcelona: Saga Editorial, 2012. 